Article

\title{
Volatility Spillovers between Equity and Green Bond Markets
}

\author{
Daehyeon Park, Jiyeon Park and Doojin Ryu *(1) \\ College of Economics, Sungkyunkwan University, Seoul 03063, Korea; pdh829@skku.edu (D.P.); \\ thkffk@skku.edu (J.P.) \\ * Correspondence: sharpjin@skku.edu
}

Received: 7 April 2020; Accepted: 1 May 2020; Published: 4 May 2020

check for updates

\begin{abstract}
This study examines the market for green bonds, which have been in the spotlight as an eco-friendly investment product. We analyze the volatility dynamics and spillovers between the equity and green bond markets. As the return dynamics of financial products typically exhibit asymmetric volatility, we check whether green bonds also share this property. Our analyses confirm that although green bonds do exhibit the asymmetric volatility phenomenon, their volatility, unlike that of equity, is also sensitive to positive return shocks. An analysis of the association between the green bond and equity markets confirms that although the two markets have some volatility spillover effects, neither responds significantly to negative shocks in the other market.
\end{abstract}

Keywords: asymmetric volatility; Baba-Engle-Kraft-Kroner model; dynamic conditional correlation-generalized autoregressive conditional heteroskedasticity; green bond; sustainable growth; G10; G11; Q56

\section{Introduction}

As interest and research in sustainable growth and corporate environmental responsibility (CER) have increased, investments in environment, social, and governance factors have also been growing. Corporate social responsibility (CSR) enhances firms' long-term performance through various channels, such as higher standard business practices and financial transparency (Popescu, 2019 [1]; Popescu and Popescu, 2019 [2]). CER is a subset of CSR, and it has been recognized as an important factor for firms' sustainability (Kim, Park, and Ryu, 2017a [3]). Indeed, investments in eco-friendly financial products are becoming more important as environmental pollution intensifies (Kim, Park, and Ryu, 2017b [4]). Accordingly, the issuances and trading volumes of green bonds, which are used to raise money for eco-friendly projects, are also increasing. Green bonds are issued mainly by international and local public organizations. These bonds are fixed-income securities such that the funds raised must be used only for eco-friendly and sustainable projects, such as renewable energy facilities. The green bond started to be issued in 2007 by the European Investment Bank for the development of technologies to improve energy efficiency or new renewable energy technologies (Banga, 2019 [5]; Hachenberg and Schiereck, 2018 [6]; Tang and Zhang, 2020 [7]).

Green bonds are considered stable and sustainable investments in terms of funding for long-term social projects. Eco-friendly infrastructure and sustainable projects, such as wind and solar energy facilities, are long-term projects that require vast amounts of funding. Thus, raising funds through a large bond market that can provide capital over a long period of time might be an appropriate choice. For investors, green bonds are stable investments that provide long-term income. Moreover, because green bonds are issued for social purposes, the political and social demands for the bonds are growing. Thus, green bonds provide an advantage for investors by allowing them to carry out their green initiatives without burdening their portfolios. Traditional eco-friendly financial products 
are difficult to integrate into a portfolio owing to their variable interest payments, maturity adjustments, and liquidity constraints. In contrast, green bonds are relatively easy to integrate into portfolios because their issuance method is similar to that of traditional government bonds.

Because of these advantages, green bonds circulate actively in the market, and academic researchers continue to study them accordingly. Green bonds can be analyzed by considering the general characteristics of bonds, and a long-standing research interest related to the bond market is its association with the equity market. The mechanism by which volatility is transferred between the equity and bond markets plays an important role in portfolio composition and risk management. In portfolio composition, bonds are relatively stable assets compared to stocks and, thus, can offset the risk of stocks in a portfolio. Many previous studies, therefore, analyze the dynamic relationship between the equity and bond markets (Cappiello, Engle, and Sheppard, 2006 [8]; Christiansen, 2010 [9]; Chuliá and Torro, 2008 [10]; Dean, Faff, and Loudon, 2010 [11]; Fleming, Kirby, and Ostdiek, 1998 [12]; Steeley, 2006 [13]). Because green bonds are a type of bond, analyzing the relationship between the green bond and stock markets should help investors organize their portfolios. However, because green bonds just started to be actively traded recently, academic research on this topic is insufficient.

Thus, this study presents meaningful conclusions about the correlation between the green bond and stock markets and the characteristics of the green bond market by analyzing the volatilities of green bond and stock indices. Both bond and stock markets generally exhibit an asymmetric volatility that reacts more sensitively to negative shocks. Thus, we also test for the presence of asymmetric volatility in the green bond and stock markets. In addition, we utilize the Baba-Engle-Kraft-Kroner (BEKK) model and the dynamic conditional correlation-generalized autoregressive conditional heteroskedasticity (DCC-GARCH) model to analyze the volatility spillovers between the two markets. We consider that previous studies empirically and widely use the multivariate GARCH models (Kim and Ryu, 2014 [14]; Park, Ryu, and Song, 2017 [15]; Ryu and Shim, 2017 [16]; Sayed and Auret, 2020 [17]; Shim, Kim, and Ryu, 2017 [18]; Song, Park, and Ryu, 2018 [19], Vardar, Coskun, and Yelkenci, 2018 [20]).

The remainder of this paper is organized as follows. We review the literature related to the green bond market, the relationship between bond and equity markets, and the asymmetric volatility of financial products in Section 2. We then describe our data and conduct preliminary tests in Section 3. We provide the empirical results and interpretations regarding asymmetric volatility in the green bond market and volatility spillovers between the two markets in Section 4, and we draw conclusions in Section 5 .

\section{Literature Review}

Because the green bond market has emerged recently, most prior studies on this market conduct basic financial analyses. Pham (2016) [21] uses the GARCH model to analyze the volatilities of the green and traditional bond markets using the S\&P (Standard \& Poor's: S\&P Global Ratings, NY, USA) Green Bond Index, the S\&P Green Project Bond Index, and the S\&P U.S. Aggregate Bond Index to identify spillover effects. Reboredo (2018) [22] uses a threshold GARCH model to show that green bonds do not provide diversification effects to traditional bond market investors. He also argues that it is important to analyze the links between the markets for green bonds and other financial instruments based on green bonds' relationship with the stock and energy commodity markets.

The relationship between equity and bond markets has been studied for a long time. However, no unified relationship exists to describe the connection between the two markets. Campbell and Vuolteenaho (2004) [23] use the vector autoregressive model to demonstrate different changes in future cash flows and changes in discount rates in both markets. Steeley (2006) [13] analyzes the link between British short- and long-term bonds and stocks and shows that the returns in the two markets are negatively correlated. Christiansen (2010) [9] uses a bivariate GARCH model to analyze volatility spillover effects in the United States and England, and shows that each market's volatility is more affected by its own volatility than by that of the other market. These previous studies show somewhat inconsistent results depending on the region, financial products, and sample periods. 
Volatility dynamics are an on-going hot research topic in the field of economics (Kim, Park, and Ryu, 2018 [24]; Kim and Ryu, 2015a, 2015b [25,26]; Chun, Cho, and Ryu, 2019, 2020 [27,28]; Lee and Ryu, 2014a, 2014b [29,30]). For example, some previous studies analyze the relationship between volatility movements and economic factors in financial markets (Shim, Kim, Kim, and Ryu, 2015 [31]; Lee and Ryu, 2018 [32]; Lee and Ryu, 2019 [33]). Other studies examine the return and volatility transmissions between related markets (Guo, Han, Liu, and Ryu, 2013 [34]; Kim, Ryu, Seo, 2015 [35]; Lee, Kang, and Ryu, 2015 [36]; Lee and Ryu, 2016 [37]; Lee, Lee, and Ryu, 2019 [38]). The more recent studies introduce the cross-market effects in explaining return dynamics, volatility dynamics, and volatility spillovers, aiming to broaden our knowledge on the volatility dynamics (Han, Kutan, and Ryu, 2015 [39]; Izadi and Hassan, 2018 [40]; Park, Kutan, and Ryu, 2019 [41]; Song, Ryu, and Webb, 2016, 2018 [42,43]; Yang, Kim, Kim, and Ryu, 2018 [44]).

In the field of finance and market microstructure, the studies on volatility have somewhat different focuses. For example, they examine the information contents of option-implied volatilities (Ryu, 2012 [45]; Ryu, Kang, and Suh, 2015 [46]), investigate whether trading volume and activities predict future volatilities (Ryu and Yang, 2020 [47]), and test which investors have an information advantage in volatility dynamics (Ryu and Yang, 2019 [48]; Ryu, Ryu, and Yang, 2020 [49]; Yang, Kutan, and Ryu, 2019 [50]).

In particular, existing studies in financial economics have continuously reported the asymmetric volatility phenomenon. In a pioneering study of asymmetric volatility, Black (1976) [51] and Christie (1982) [52] reveal that negative price shocks lead to higher volatility than positive shocks in the stock market. They argue that the leverage effect is the cause of asymmetric volatility. In contrast, Pindyck (1984) [53], French, Schwert, and Stambaugh (1987) [54], and Campbell and Hentschel (1992) [55] argue for the volatility feedback hypothesis. More recently, Hibbert, Daigler, and Dupoyet (2008) [56] and Han, Guo, Ryu, and Webb (2012) [57] examine the asymmetric volatility based on the behavioral explanation.

Following these studies, researchers have materially and empirically investigated asymmetric volatility as a feature of financial time series data. Understanding asymmetric volatility helps to increase the accuracy of predictions. Kroner and $\mathrm{Ng}$ (1998) [58] use the asymmetric bivariate GARCH model to show that the covariance matrix of returns to the stocks of large and small businesses is asymmetric about signals of return shocks. Koutmos (1999) [59] shows that positive returns are sustained longer than negative ones in an emerging Asian stock market. Cappiello, Engle, and Sheppard (2006) [8] argue that stock returns strongly exhibit asymmetry in their conditional variance, whereas little asymmetry is observed in bond returns. In addition, both stocks and bonds exhibit asymmetry in their conditional correlation. Stocks react more sensitively to negative shocks than bonds do. Chuliá and Torro (2008) [10] use an asymmetric multivariate GARCH model to consider volatility spillovers between European equity and bond markets and a dynamic trading strategy. Volatility is transferred in both directions. However, the conditional variance for stocks is asymmetric to shocks in both markets, whereas the conditional variance for bonds reacts asymmetrically only to stock market shocks. Dean, Faff, and Laudon (2010) [11] use a bivariate GARCH model to analyze the asymmetric volatility and spillover effects in daily returns to the Australian stock and bond markets. Lee and Ryu (2013) [60] suggest a vector autoregressive (VAR) framework to examine the asymmetric volatility. Based on these studies, we can expect the green bond market to exhibit asymmetric volatility as well.

\section{Predictive Regression Models}

\subsection{Data Description}

Because the purpose of this study is to analyze the stock and green bond markets, we carry out the analysis by converting the indices representing the two markets into return series. We use the S\&P 500 Index to represent the stock market price and the S\&P Green Bond Select Index, developed by Standard \& Poor's, to reflect the green bond market. Standard \& Poor's began publishing the S\&P Green Bond 
index as a general index of green bonds. More recently, the S\&P Global Ratings started separately selecting the green bonds that are highly relevant to the stock market, and it now releases the S\&P Green Bond Select index as a separate index. In this study, we use the S\&P Green Bond Select index rather than the S\&P Green Bond index because we analyze the correlation between the stock market and the green bond market. The data range from January 2010 to January 2020 and are converted to $\log$ returns, as shown in Equation (1).

$$
R_{i, t}=\ln \left(\frac{P_{i, t}}{P_{i, t-1}}\right)
$$

We calculate the return rates of the S\&P 500 Index and the S\&P Green Bond Select Index, which we label as SPX and GBS, respectively. Table 1 shows the descriptive statistics for each dataset. As Table 1 shows, SPX and GBS both have asymmetrical structures with negative skewness. In addition, both series have leptokurtic distributions with thick tails, as they both have high kurtosis. We reject the null hypothesis of the Jarque-Bera test for both data series, meaning that neither follows a normal distribution. The null hypothesis of the augmented Dicky-Fuller (ADF) test is rejected, meaning that there is no unit root.

Table 1. Descriptive statistics.

\begin{tabular}{ccc}
\hline & SPX & GBS \\
\hline Mean & 0.0002 & 0.0001 \\
\hline Max & 0.0210 & 0.0118 \\
\hline Median & -0.2995 & -0.0147 \\
\hline Min & 0.0003 & 0.0003 \\
\hline Standard deviation & 0.0040 & 0.0021 \\
\hline Skewness & -0.4980 & -0.0971 \\
\hline Kurtosis & 7.5970 & 7.1990 \\
\hline Jarque-Bera test & $2336.8^{* * *}$ & $1866.3^{* * *}$ \\
\hline ADF test & $-52.629^{* * *}$ & $-53.282^{* * *}$ \\
\hline Correlation & & \\
\hline
\end{tabular}

Note: This table summarizes the descriptive statistics of the returns to the S\&P 500 Index (SPX) and the S\&P Green Bond Select Index (GBS). The rows for the Jarque-Bera and Dicky-Fuller (ADF) tests report $t$-statistics. ${ }^{* * *}$ means that the test is significant at the $1 \%$ level.

\subsection{Preliminary Test}

This section tests whether SPX and GBS are suitable for the analysis in Section 4. First, we check the volatility clustering of SPX and GBS. Figure 1 shows a graphical representation of the two data series, and the volatility clusters of both series can be identified from these graphs. 


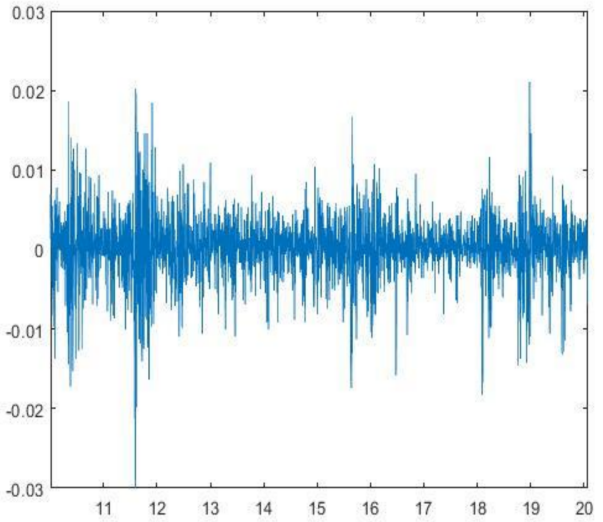

Panel A. SPX

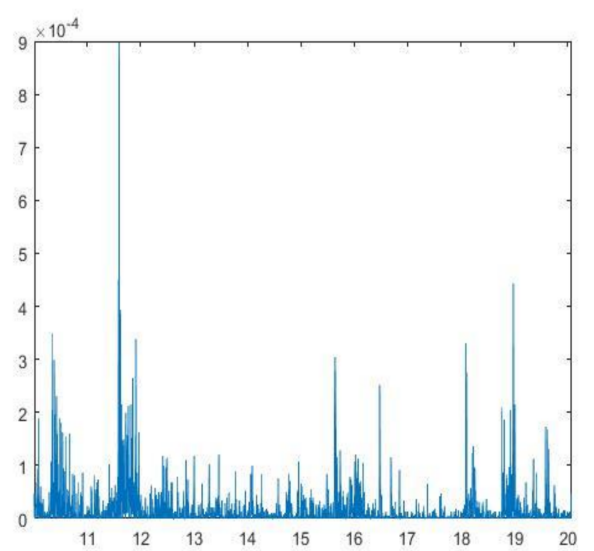

Panel C. SPX²

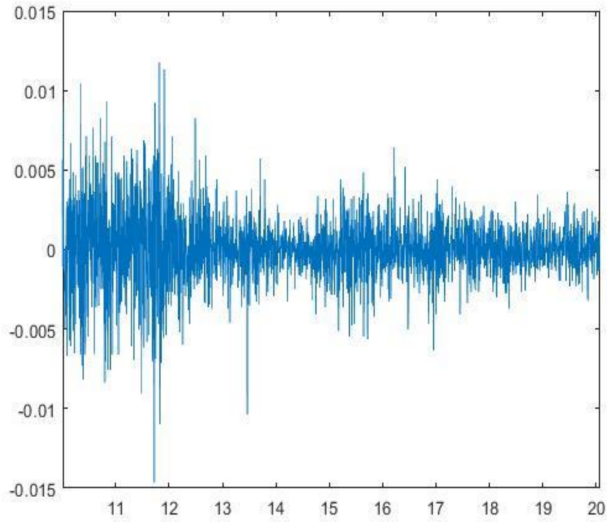

Panel B. GBS

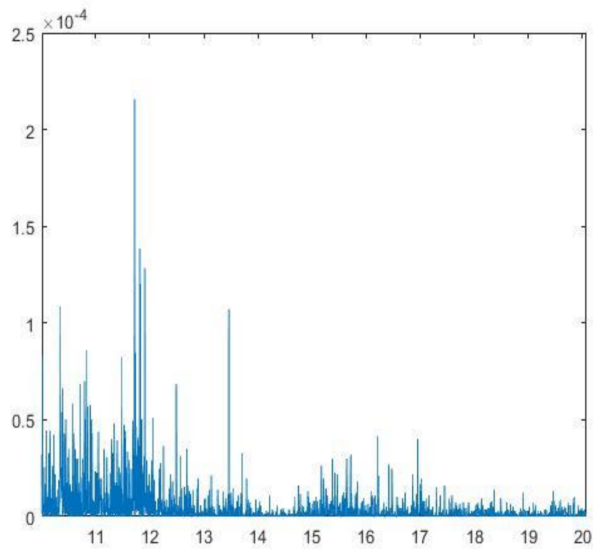

Panel D. GBS ${ }^{2}$

Figure 1. Time series of SPX and GBS returns and squared returns. Note: This figure depicts the time series of S\&P 500 Index (SPX) returns and squared returns and S\&P Green Bond Select Index (GBS) returns and squared returns. Panels A and B show the time series of SPX and GBS returns, respectively, and Panels $\mathbf{C}$ and $\mathbf{D}$ show the time series of squared SPX and GBS returns, respectively.

In Panels A and B of Figure 1, both time series observations appear to follow a white noise process, but volatility clusters appear to exist. These patterns are more evident in Panels C and D, which show squared returns. Figure 2, which shows the autocorrelation between the two data series, reveals volatility clustering more clearly. Additionally, the Ljung-Box Q-statistic of each time lag is above the critical value for Panels $C$ and D, demonstrating the autocorrelation in the squared returns and, thus, in the volatilities of SPX and GBS. This result means that both data series have an ARCH effect, meaning that the GARCH family of models is suitable for analyzing both indices. Table 2 shows the results of the Ljung-Box test for the returns and squared returns of SPX and GBS, and these results lead to the same conclusions as Figures 1 and 2. 


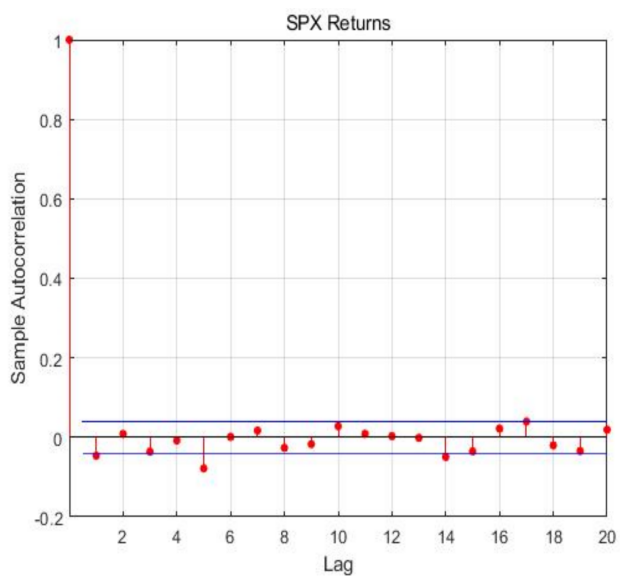

Panel A. AC of SPX

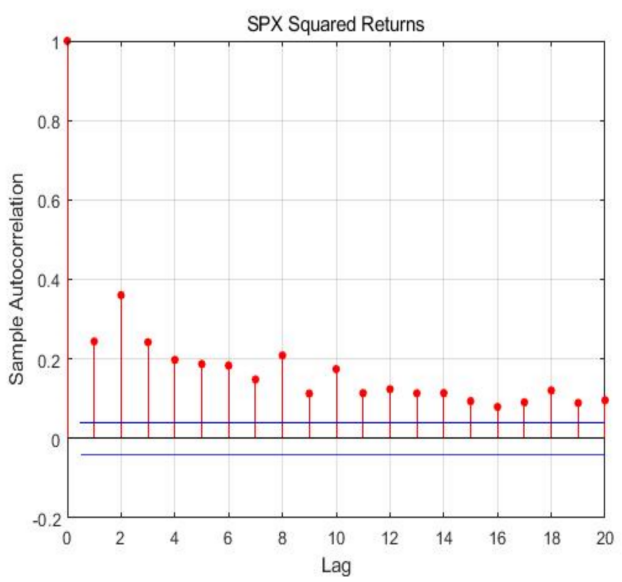

Panel C. AC of SPX²

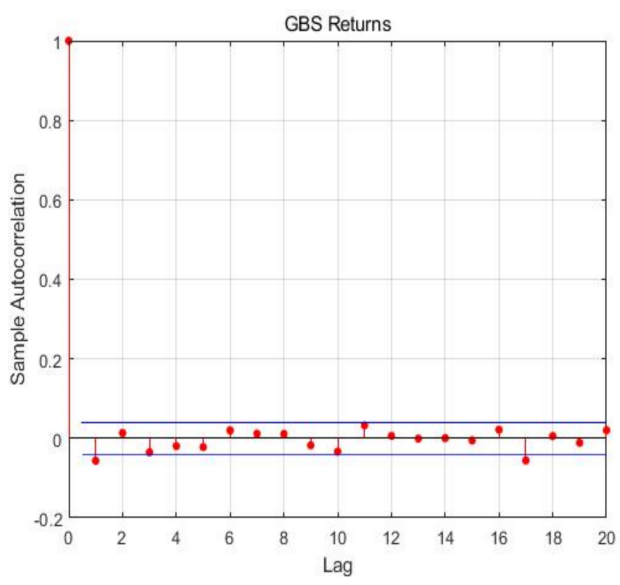

Panel B. AC of GBS

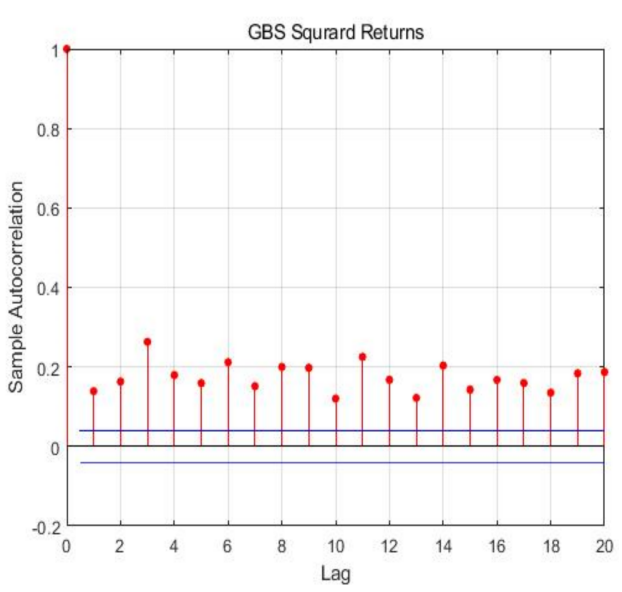

Panel D. AC of GBS 2

Figure 2. Autocorrelation. Note: This figure depicts the autocorrelation (AC) in each index. SPX indicates S\&P 500 Index returns, and GBS indicates S\&P Green Bond Select Index returns. Panels A and B show the autocorrelation in SPX and GBS returns, respectively, and Panels C and D show the autocorrelation in SPX and GBS squared returns, respectively.

Table 2. Ljung-Box test.

\begin{tabular}{ccc}
\hline & SPX & GBS \\
\hline LB(10) returns & $0.0298 \mathrm{~b}^{* * *}$ & $0.0191 \mathrm{~b}^{* *}$ \\
$\mathrm{LB}(10)$ squared returns & $1.1800 \mathrm{~b}^{* * *}$ & $0.8490 \mathrm{~b}^{* *}$ \\
\hline
\end{tabular}

Note: This table shows the results of the Ljung-Box test for the returns and squared returns of the S\&P 500 Index (SPX) and the S\&P Green Bond Select Index (GBS). The row labeled "LB(10) returns" shows Ljung-Box statistics with ten lags for the returns to each index, and the row labeled " $\mathrm{LB}(10)$ squared returns" shows Ljung-Box statistics with ten lags for the squared returns to each index. ${ }^{* *}$ and ${ }^{* * *}$ indicate significance at the $5 \%$ and $1 \%$ level, respectively.

\section{Empirical Analyses and Results}

\subsection{Asymmetric Volatility}

The analysis described in this section tests for asymmetric volatility in the stock and green bond markets. As discussed in Section 2, financial data generally exhibit asymmetric volatility. Dean, Faff, and Loudon (2010) [11] find that the Australian stock and bond markets exhibit asymmetric volatility. Thus, in this study, we also check the volatilities of the stock and green bond markets for asymmetry. To this end, we implement the sign and size bias tests proposed by Engle and Ng (1993) [61]. These tests determine the significance of volatility changes when a negative or positive return shock occurs by 
regressing the squared residual term on a dummy variable reflecting the sign of the residual term. Using $\epsilon_{i, t}, i=S P X, G B S$ to indicate the residual of asset $i$ at time $t$, we perform each test by estimating the following regressions.

$$
\begin{gathered}
\text { Signbiastest } \epsilon_{i, t}^{2}=a+b S_{i, t-1}^{-}+u_{i, t} . \\
\text { Negativesizebiastest } \epsilon_{i, t}^{2}=a+b S_{i, t-1}^{-} \epsilon_{i, t-1}+u_{i, t} . \\
\text { Positivesizebiastest } \epsilon_{i, t}^{2}=a+b S_{i, t-1}^{+} \epsilon_{i, t-1}+u_{i, t} . \\
\text { Jointbiastest } \epsilon_{i, t}^{2}=a+b_{1} S_{i, t-1}^{-}+b_{2} S_{i, t-1}^{-} \epsilon_{i, t-1}+b_{3} S_{i, t-1}^{+} \epsilon_{i, t-1}+u_{i, t} .
\end{gathered}
$$

$S_{i, t-1}^{-}$and $S_{i, t-1}^{+}$are dummy variables that take a value of one for negative and positive residuals of $i$, respectively. Table 3 presents the results.

Table 3. Bias test.

\begin{tabular}{ccc}
\hline & SPX & GBS \\
\hline Sign bias test & $4.1875^{* * *}$ & 1.3341 \\
Negative size bias test & $-10.940^{* * *}$ & $-7.8589^{* * *}$ \\
Positive size bias test & 0.68606 & $2.272^{* *}$ \\
Joint bias test & $46.4^{* * *}$ & $30.4^{* * *}$ \\
\hline
\end{tabular}

Note: This table shows the results of conducting the bias test proposed by Engle and $\mathrm{Ng}$ (1993) [61] for the residuals of S\&P 500 Index (SPX) returns and S\&P Green Bond Select Index (GBS) returns. The sign, negative size, and positive size bias tests are conducted using $t$-tests in Equations (2)-(4), and the joint bias test is conducted using an $F$-test in Equation (5). Each number in the table is a $t$-statistic or an $F$-statistic value. ${ }^{* *}$ and ${ }^{* * *}$ indicate significance at the $5 \%$ and $1 \%$ level, respectively.

Table 3 shows that SPX follows the typical form of asymmetric volatility, as sensitivity to negative shocks is observed. However, for GBS, the coefficient of $S_{i, t-1}^{-}$is not significant, whereas the coefficients and models for the other tests are all significant. Generally, financial instruments respond more sensitively to bad news than to good news, which seems to reflect some investors' tendency to hedge. In the case of GBS, however, volatility is also sensitive to the positive return shock. These results may be driven by the recent positive market response to eco-friendly financial instruments. In other words, as green bonds are experiencing rapid growth in recent years, investors view them hopefully and react strongly to minor pieces of good news, resulting in increased volatility. GBS also exhibits asymmetric volatility, as its volatility reacts differently to negative and positive shocks. However, given that Dean, Faff, and Loudon (2010) [11] find that the volatility in the Australian bond market is asymmetrical and sensitive to negative return shocks, green bonds have slightly different characteristics from those of conventional bonds.

\subsection{Bivariate GARCH Estimation}

In this section, we analyze volatility transfers between the two markets using a bivariate GARCH model. The earlier tests show that the volatilities of SPX and GBS exhibit ARCH effects and have asymmetrical characteristics. Thus, the correlation between the two markets indicates that the BEKK and DCC-GARCH models, which can reflect asymmetric volatility, are appropriate in this context. GARCH family models are represented by a conditional mean process and a conditional variance process. In this study, the conditional mean processes of models are defined as shown in Equations (6) and (7) because we focus on the analysis of the volatility spillover. In the subsequent analyses, we use $i=1$ to mean SPX and $i=2$ to mean GBS for convenience. $\epsilon_{t}$ is a residual vector following a multivariate normal distribution with $E_{t-1}\left(\epsilon_{t}\right)=0$ and $E_{t-1}\left(\epsilon_{t} \epsilon_{t}^{\prime}\right)=H_{t}$.

$$
r_{i, t}=\mu_{i, t}+\epsilon_{i, t}, \text { for } i=1,2
$$




$$
\epsilon_{t}=\left[\begin{array}{c}
\epsilon_{1, t} \\
\epsilon_{2, t}
\end{array}\right] \sim N\left(0, H_{t}\right)
$$

The BEKK model presented by Engle and Kroner (1995) [62] has the conditional variance process given by Equations (8).

$$
\begin{gathered}
H_{t}=C^{\prime} C+A^{\prime} \epsilon_{t-1} \epsilon_{t-1}^{\prime} A+B^{\prime} H_{t-1} B \\
\text { where } H_{t}=\left[\begin{array}{ll}
h_{11, t} & h_{12, t} \\
h_{21, t} & h_{22, t}
\end{array}\right], C=\left[\begin{array}{cc}
c_{11} & c_{12} \\
0 & c_{22}
\end{array}\right], A=\left[\begin{array}{ll}
a_{11} & a_{12} \\
a_{21} & a_{22}
\end{array}\right], B=\left[\begin{array}{ll}
b_{11} & b_{12} \\
b_{21} & b_{22}
\end{array}\right] .
\end{gathered}
$$

The BEKK model is intuitive and suitable for describing volatility spillovers. It can be transformed into the asymmetric BEKK model to reflect asymmetrical volatility (Kroner and Ng, 1998 [58]), as shown in Equations (9).

$$
\begin{gathered}
H_{t}=C^{\prime} C+A^{\prime} \epsilon_{t-1} \epsilon_{t-1}^{\prime} A+B^{\prime} H_{t-1} B+G^{\prime} \eta_{t-1} \eta_{t-1} G, \\
\text { where } H_{t}=\left[\begin{array}{ll}
h_{11, t} & h_{12, t} \\
h_{21, t} & h_{22, t}
\end{array}\right], C=\left[\begin{array}{cc}
c_{11} & c_{12} \\
0 & c_{22}
\end{array}\right], A=\left[\begin{array}{ll}
a_{11} & a_{12} \\
a_{21} & a_{22}
\end{array}\right], B=\left[\begin{array}{ll}
b_{11} & b_{12} \\
b_{21} & b_{22}
\end{array}\right], \\
G=\left[\begin{array}{ll}
g_{11} & g_{12} \\
g_{21} & g_{22}
\end{array}\right], \eta_{t-1}=\left[\begin{array}{c}
\max \left(0,-\epsilon_{1, t-1}\right) \\
\max \left(0,-\epsilon_{2, t-1}\right)
\end{array}\right]
\end{gathered}
$$

\begin{tabular}{|c|c|c|c|c|c|}
\hline \multicolumn{3}{|c|}{ Panel A. Symmetric BEKK } & \multicolumn{3}{|c|}{ Panel B. Asymmetric BEKK } \\
\hline$c_{11}$ & $0.0010^{* * *}$ & (9.1423) & $c_{11}$ & $-0.0008 * * *$ & $(-15.7276)$ \\
\hline$c_{12}$ & $-0.0081^{* * *}$ & $(-12.5446)$ & $c_{12}$ & $-0.0018^{* * *}$ & $(-16.7175)$ \\
\hline$c_{22}$ & $0.0001 * * *$ & $(7.8447)$ & $c_{22}$ & $-0.0027^{* * *}$ & $(-105.4916)$ \\
\hline$a_{11}$ & $0.2523^{* * *}$ & (12.2209) & $a_{11}$ & $0.1598^{* * *}$ & $(9.3944)$ \\
\hline$a_{12}$ & 0.0065 & $(0.4422)$ & $a_{12}$ & $0.1449^{* * *}$ & (3.3753) \\
\hline$a_{21}$ & $0.0671^{* * *}$ & (3.2148) & $a_{21}$ & $-0.0931 * * *$ & $(-6.4990)$ \\
\hline$a_{22}$ & $0.2464^{* * *}$ & (11.3875) & $a_{22}$ & $0.1593^{* * *}$ & $(20.7743)$ \\
\hline$b_{11}$ & $0.9136^{* * *}$ & (51.8925) & $b_{11}$ & $0.8875 * * *$ & $(6.7269)$ \\
\hline$b_{12}$ & $-0.0680 * * *$ & $(-6.9604)$ & $b_{12}$ & 0.0056 & $(-0.3462)$ \\
\hline$b_{21}$ & $0.1020^{* * *}$ & $(5.7324)$ & $b_{21}$ & 0.0062 & $(-0.8648)$ \\
\hline \multirow[t]{5}{*}{$b_{22}$} & $0.8881 * * *$ & $(95.3600)$ & $b_{22}$ & $0.9270^{* * *}$ & $(4.3252)$ \\
\hline & & & $g_{11}$ & $0.4044^{* * *}$ & (67.5478) \\
\hline & & & $g_{12}$ & -0.0293 & $(1.3163)$ \\
\hline & & & $g_{21}$ & -0.0281 & $(0.4498)$ \\
\hline & & & $g_{22}$ & $0.2068^{* * *}$ & (500.9299) \\
\hline LogLike & \multicolumn{2}{|c|}{22828.923} & LogLike & \multicolumn{2}{|c|}{20344.498} \\
\hline AIC & \multicolumn{2}{|c|}{-45646.846} & AIC & \multicolumn{2}{|c|}{-40673.996} \\
\hline SIC & \multicolumn{2}{|c|}{-17772.846} & SIC & \multicolumn{2}{|c|}{-2663.996} \\
\hline
\end{tabular}

A term for the negative return shock is incorporated. $\eta_{t}$ is a vector of negative residuals. Thus, the product of the matrix $\mathrm{G}$ and $\eta_{t}$ reflects the asymmetrical change in volatility response to the negative shock. Table 4 shows the estimates of the BEKK model for the stock and green bond markets.

Table 4. Baba-Engle-Kraft-Kroner (BEKK) estimation.

Note: This table estimates the parameters of the symmetric and asymmetric BEKK models for S\&P 500 Index returns and S\&P Green Bond Select Index returns. Panel A shows the estimation of Equation (8), and Panel B shows the estimation of Equation (9). The numbers in parentheses represent $t$-statistics. ${ }^{* * *}$ indicates significance at the $1 \%$ level. LogLike stands for log-likelihood value, and AIC and SIC stand for the Akaike information criterion and the Schwarz information criterion, respectively.

As Table 4 shows, the estimates of the BEKK model imply that volatility in the stock market affects volatility in the green bond market, and vice versa. However, $g_{12}$ and $g_{21}$ are not significant in Panel B, indicating that a negative shock in one market does not spread to the other market. That is, the bad news in the stock market does not create a major shock in the green bond market, and the reverse is also true. However, the BEKK model has the disadvantage of having too many parameters to estimate. Accordingly, Engle (2002) [63] proposes the DCC-GARCH model, which requires the estimation of 
fewer parameters and can analyze a multivariate GARCH model. The conditional variance process in the DCC-GARCH model is given by Equations (10) and (11). Equation (10) shows a conditional covariance. Equation (11) presents a dynamic conditional correlation.

$$
\begin{gathered}
H_{t}=D_{t} R_{t} D_{t} \text {, where } D_{t}=\operatorname{diag}\left[\sqrt{h_{i, t}}\right] \text { and } h_{i, t}=c_{i}+a_{i} \epsilon_{i, t-1}^{2}+b_{i} h_{i, t-1}, \text { for } i=1,2 . \\
R_{t}=Q_{t}^{*-1} Q_{t} Q_{t}^{*-1}, \text { where } Q_{t}^{*-1}=\operatorname{diag}\left[\sqrt{Q_{t}}\right] ; \\
Q_{t}=(1-\alpha-\beta) \bar{R}+\alpha z_{t-1} z_{t-1}^{\prime}+\beta Q_{t-1}, \text { where } z_{t-1}=\left[\begin{array}{l}
\epsilon_{1, t-1} / \sqrt{h_{1, t-1}} \\
\epsilon_{2, t-1} / \sqrt{h_{2, t-1}}
\end{array}\right], \bar{R}=E\left[z_{t-1} z_{t-1^{\prime}}\right] .
\end{gathered}
$$

As with the BEKK model, the DCC-GARCH model cannot estimate asymmetrical effects. Accordingly, Cappiello, Engle, and Sheppard (2006) [8] extend the DCC-GARCH model to the asymmetric DCC-GARCH (ADCC-GARCH) model to reflect asymmetrical effects. Equations (12) and (13) present the conditional variance process of the ADCC-GARCH model. Equation (12) shows a conditional variance with the additional term $g_{i} \eta_{i, t-1}^{2}$, which reflects the asymmetry by the definition of $\eta_{i, t}$. Equation (13) shows a dynamic conditional correlation with additional terms $-\gamma^{2} \bar{N}$ and $\gamma^{2} \eta_{t-1} \eta_{t-1}^{\prime} \cdot \gamma$ is a leverage parameter.

$$
\begin{gathered}
H_{t}=D_{t} R_{t} D_{t} \text {, where } D_{t}=\operatorname{diag}\left[\sqrt{h_{i, t}}\right] ; \\
h_{i, t}=c_{i}+a_{i} \epsilon_{i, t-1}^{2}+b_{i} h_{i, t-1}+g_{i} \eta_{i, t-1}^{2} \text {, for } i=1,2 \text {, where } \eta_{i, t-1}=\max \left(0,-\epsilon_{i, t-1}\right) . \\
R_{t}=Q_{t}^{*-1} Q_{t} Q_{t}^{*-1} \text {, where } Q_{t}^{*-1}=\operatorname{diag}\left[\sqrt{Q_{t}}\right] ; \\
Q_{t}=\left(1-\alpha^{2}-\beta^{2}\right) \bar{R}-\gamma^{2} \bar{N}+\alpha^{2} z_{t-1} z_{t-1}^{\prime}+\gamma^{2} \eta_{t-1} \eta_{t-1}+\beta^{2} Q_{t-1}, \\
\text { where } z_{t-1}=\left[\begin{array}{l}
\epsilon_{1, t-1} / \sqrt{h_{1, t-1}} \\
\epsilon_{2, t-1} / \sqrt{h_{2, t-1}}
\end{array}\right], \bar{R}=E\left[z_{t-1} z_{t-1}^{\prime}\right], \eta_{t}=\left[\begin{array}{c}
\eta_{1, t} \\
\eta_{2, t}
\end{array}\right], \bar{N}=E\left[\eta_{t} \eta_{t^{\prime}}\right]
\end{gathered}
$$

Thus, we estimated the DCC-GARCH model, as shown in Table 5.

Table 5. DCC-GARCH estimation.

\begin{tabular}{cccccc}
\hline \multicolumn{2}{c}{ Panel A. Symmetric DCC-GARCH } & \multicolumn{3}{c}{ Panel B. Asymmetric DCC-GARCH } \\
\hline$c_{1}$ & $0.0000^{* * *}$ & $(4.4884)$ & $c_{1}$ & $0.0000^{* * *}$ & $(4.4884)$ \\
$c_{2}$ & 0.0000 & $(1.5180)$ & $c_{2}$ & $0.0000^{*}$ & $(1.8203)$ \\
$a_{1}$ & $0.1648^{* * *}$ & $(6.4289)$ & $a_{1}$ & $0.0000^{* *}$ & $(2.3922)$ \\
$a_{2}$ & $0.0319^{* * *}$ & $(4.5130)$ & $a_{2}$ & $0.0264^{* *}$ & $(2.5715)$ \\
$b_{1}$ & $0.7950^{* * *}$ & $(30.3176)$ & $b_{1}$ & $0.7950^{* * *}$ & $(30.3176)$ \\
$b_{2}$ & $0.9649^{* * *}$ & $(130.1763)$ & $b_{2}$ & $0.9666^{* * *}$ & $(142.6195)$ \\
& & & $g_{1}$ & $0.27944^{* * *}$ & $(7.1945)$ \\
& & & $g_{2}$ & 0.0076 & $(0.5427)$ \\
$\alpha$ & $0.0202^{*}$ & $(1.8399)$ & $\alpha$ & 0.0193 & $(1.4769)$ \\
$\beta$ & $0.9764^{* * *}$ & $(69.4404)$ & $\beta$ & $0.9728^{* * *}$ & $(21.4186)$ \\
\multicolumn{2}{c}{} & & $\gamma$ & 0.0092 & $(0.0852)$ \\
\hline LogLike & 23374.415 & LogLike & \multicolumn{2}{c}{23374.881} \\
AIC & -46739.830 & AIC & -46736.762 \\
SIC & -23933.830 & SIC & -13794.762 \\
\hline
\end{tabular}

Note: This table estimates the parameters of the symmetric and asymmetric DCC-GARCH models for S\&P 500 Index returns and S\&P Green Bond Select Index returns. Panel A shows the estimation of Equations (10) and (11), and Panel B shows the estimation of Equations (12) and (13). The numbers in parentheses are $t$-statistics. ${ }^{*}, * *$, and ${ }^{* * *}$ indicate significance at the $10 \%, 5 \%$, and $1 \%$ level, respectively. LogLike stands for log-likelihood value, and AIC and SIC stand for the Akaike information criterion and the Schwarz information criterion, respectively.

The estimated results shown in Table 5 are similar to those shown in Table 4. Panels A and $\mathrm{B}$ both have significant coefficients, confirming the volatility transfers between the two markets. However, when we estimate the ADCC-GARCH model, we can conclude that the volatility transfer 
between the two markets is not asymmetric, given that the coefficient $\gamma$ is not significantly different from zero.

\section{Conclusions}

This study presents an econometric analysis of the green bond market. In particular, we analyze the relationship between the green bond and equity markets. We test whether green bonds exhibit asymmetric volatility and confirm that although green bonds do exhibit asymmetrical volatility, they have the unique characteristic that their volatility is sensitive to positive shocks, unlike other financial instruments. We also analyze the association between the green bond and equity markets and confirm that the two markets have some volatility spillover effects but that neither responds significantly to negative shocks in the other market. This analysis is expected to help investors and policymakers make decisions because it newly identifies some characteristics of green bonds.

However, this study only focuses on the volatilities of both markets, and it may be extended by considering different conditional mean processes. Through such analyses, finding evidence regarding the specific correlations between the returns of the two markets is expected to provide meaningful academic discussions on green bonds.

Author Contributions: Proposal \& Original Idea, D.P. and J.P.; Conceptualization, D.P. and D.R.; Modeling, D.P. and D.R.; Methodology, D.P. and J.P.; Data Construction, D.P. and J.P.; Empirical Test, D.P.; Validation, D.R.; Resources, D.R.; Software, D.P.; Literature Review, D.P., J.P. and D.R.; Economic \& Business Implication, D.R.; Writing-Original Draft Preparation, D.P., J.P., and D.R.; Writing-Review \& Editing, D.R.; Discussion, D.P. and D.R.; Project Administration, D.R. All authors have read and agreed to the published version of the manuscript.

Funding: This work was supported by a grant from the National Research Foundation of Korea (NRF), funded by the Korea government (MSIT; Ministry of Science and ICT) [grant number: 2019R1G1A1100196].

Acknowledgments: This paper was presented in the Financial Market Microstructure seminar course at Sungkyunkwan University. We are grateful for the valuable comments of Jinyoung Yu and two anonymous referees.

Conflicts of Interest: The authors declare no conflict of interest.

\section{References}

1. Popescu, C.R.G. Corporate social responsibility, corporate governance, and business performance: Limits and challenges imposed by the implementation of directive 2013/34/EU in Romania. Sustainability 2019, 11, 5146. [CrossRef]

2. Popescu, C.R.G.; Popescu, G.N. An exploratory study based on a questionnaire concerning green and sustainable finance, corporate social responsibility, and performance: Evidence from the Romanian business environment. J. Risk Fin. Manag. 2019, 12, 162. [CrossRef]

3. Kim, H.; Park, K.; Ryu, D. Corporate environmental responsibility: A legal origins perspective. J. Bus. Eth. 2017, 140, 381-402. [CrossRef]

4. Kim, J.; Park, Y.J.; Ryu, D. Stochastic volatility of the futures prices of emission allowances: A Bayesian approach. Phys. A Stat. Mech. Appl. 2017, 465, 714-724. [CrossRef]

5. Banga, J. The green bond market: A potential source of climate finance for developing countries. J. Sustain. Fin. Invest. 2019, 9, 17-32. [CrossRef]

6. Hachenberg, B.; Schiereck, D. Are green bonds priced differently from conventional bonds? J. Asset Manag. 2018, 19, 371-383. [CrossRef]

7. Tang, D.Y.; Zhang, Y. Do shareholders benefit from green bonds? J. Corp. Fin. 2020, 61, 101427. [CrossRef]

8. Cappiello, L.; Engle, R.F.; Sheppard, K. Asymmetric dynamics in the correlations of global equity and bond returns. J. Fin. Econ. 2006, 4, 537-572. [CrossRef]

9. Christiansen, C. Decomposing European bond and equity volatility. Int. J. Fin. Econ. 2010, 15, 105-122.

10. Chuliá, H.; Torro, H. The economic value of volatility transmission between the stock and bond markets. J. Fut. Mark. 2008, 28, 1066-1094. [CrossRef]

11. Dean, W.G.; Faff, R.W.; Loudon, G.F. Asymmetry in return and volatility spillover between equity and bond markets in Australia. Pac. Basin Fin. J. 2010, 18, 272-289. [CrossRef]

12. Fleming, J.; Kirby, C.; Ostdiek, B. Information and volatility linkages in the stock, bond, and money markets. J. Fin. Econ. 1998, 49, 111-137. [CrossRef] 
13. Steeley, J.M. Volatility transmission between stock and bond markets. J. Int. Fin. Mark. Inst. Money 2006, 16, 71-86. [CrossRef]

14. Kim, J.S.; Ryu, D. Intraday price dynamics in spot and derivatives markets. Phys. A Stat. Mech. Appl. 2014, 394, 247-253. [CrossRef]

15. Park, S.Y.; Ryu, D.; Song, J. The dynamic conditional relationship between stock market returns and implied volatility. Phys. A Stat. Mech. Appl. 2017, 482, 638-648. [CrossRef]

16. Ryu, D.; Shim, H. Intraday dynamics of asset returns, trading activities, and implied volatilities: A trivariate GARCH framework. Romanian J. Econ. Forecast. 2017, 20, 45-61.

17. Sayed, A.; Auret, C. Volatility transmission in the South African white maize futures market. Euras. Econ. Rev. 2020, 10, 71-88. [CrossRef]

18. Shim, H.; Kim, M.H.; Ryu, D. Effects of intraday weather changes on asset returns and volatilities. Proc. Rijeka Faculty Econ. J. Econ. Bus. 2017, 35, 301-330. [CrossRef]

19. Song, W.; Park, S.Y.; Ryu, D. Dynamic conditional relationships between developed and emerging markets. Phys. A Stat. Mech. Appl. 2018, 507, 534-543. [CrossRef]

20. Vardar, G.; Coskun, Y.; Yelkenci, T. Shock transmission and volatility spillover in stock and commodity markets: evidence from advanced and emerging markets. Euras. Econ. Rev. 2018, 8, 231-255. [CrossRef]

21. Pham, L. Is it risky to go green? A volatility analysis of the green bond market. J. Sustain. Fin. Invest. 2016, 6, $263-291$.

22. Reboredo, J.C. Green bond and financial markets: Co-movement, diversification and price spillover effects. Energy Econ. 2018, 74, 38-50. [CrossRef]

23. Campbell, J.; Vuolteenaho, T. Bad beta, good beta. Am. Econ. Rev. 2004, 94, 1249-1275. [CrossRef]

24. Kim, J.; Park, Y.J.; Ryu, D. Testing CEV stochastic volatility models using implied volatility index data. Phys. A Stat. Mech. Appl. 2018, 499, 224-232. [CrossRef]

25. Kim, J.S.; Ryu, D. Return and volatility spillovers and cojump behavior between the U.S. and Korean stock markets. Emerg. Mark. Fin. Trade 2015, 51, S3-S17. [CrossRef]

26. Kim, J.S.; Ryu, D. Are the KOSPI 200 implied volatilities useful in value-at-risk models? Emerg. Mark. Rev. 2015, 22, 43-64. [CrossRef]

27. Chun, D.; Cho, H.; Ryu, D. Forecasting the KOSPI200 spot volatility using various volatility measures. Phys. A Stat. Mech. Appl. 2019, 514, 156-166. [CrossRef]

28. Chun, D.; Cho, H.; Ryu, D. Economic indicators and stock market volatility in an emerging economy. Econ. Syst. 2020. forthcoming.

29. Lee, C.; Ryu, D. The volatility index and style rotation: Evidence from the Korean stock market and VKOSPI. Invest. Anal. J. 2014, 43, 29-39. [CrossRef]

30. Lee, J.; Ryu, D. Regime-dependent relationships between the implied volatility index and stock market index. Emerg. Mark. Fin. Trade 2014, 50, 5-17.

31. Shim, H.; Kim, H.; Kim, J.; Ryu, D. Weather and stock market volatility: The case of a leading emerging market. Appl. Econ. Lett. 2015, 22, 987-992. [CrossRef]

32. Lee, G.; Ryu, D. Asymmetry in the stock price response to macroeconomic shocks: Evidence from the Korean market. J. Bus. Econ. Manag. 2018, 19, 343-359. [CrossRef]

33. Lee, J.; Ryu, D. The impacts of public news announcements on intraday implied volatility dynamics. J. Fut. Mark. 2019, 39, 656-685. [CrossRef]

34. Guo, B.; Han, Q.; Liu, M.; Ryu, D. A tale of two index futures: The intraday price discovery and volatility transmission processes between the China financial futures exchange and the Singapore exchange. Emerg. Mark. Fin. Trade 2013, 49, 197-212. [CrossRef]

35. Kim, J.S.; Ryu, D.; Seo, S.W. Corporate vulnerability index as a fear gauge? Exploring the contagion effect between U.S. and Korean markets. J. Derivat. 2015, 23, 73-88. [CrossRef]

36. Lee, J.; Kang, J.; Ryu, D. Common deviation and regime-dependent dynamics in the index derivatives markets. Pac. Basin Fin. J. 2015, 33, 1-22. [CrossRef]

37. Lee, J.; Ryu, D. Asymmetric mispricing and regime-dependent dynamics in futures and options markets. Asian Econ. J. 2016, 30, 47-65. [CrossRef]

38. Lee, J.; Lee, G.; Ryu, D. The difference in the intraday return-volume relationships of spot and futures: A quantile regression approach. Economics 2019, 13, 1-37. [CrossRef]

39. Han, H.; Kutan, A.M.; Ryu, D. Effects of the US stock market return and volatility on the VKOSPI. Economics 2015, 9, 1-34. [CrossRef] 
40. Izadi, S.; Hassan, M.K. Portfolio and hedging effectiveness of financial assets of the G7 countries. Euras. Econ. Rev. 2018, 8, 183-213. [CrossRef]

41. Park, Y.J.; Kutan, A.M.; Ryu, D. The impacts of overseas market shocks on the CDS-option basis. North Am. J. Econ. Fin. 2019, 47, 622-636. [CrossRef]

42. Song, W.; Ryu, D.; Webb, R.I. Overseas market shocks and VKOSPI dynamics: A Markov-switching approach. Fin. Res. Lett. 2016, 16, 275-282. [CrossRef]

43. Song, W.; Ryu, D.; Webb, R.I. Volatility dynamics under an endogenous Markov-switching framework: A cross-market approach. Quant. Fin. 2018, 18, 1559-1571. [CrossRef]

44. Yang, E.; Kim, S.H.; Kim, M.H.; Ryu, D. Macroeconomic shocks and stock market returns: The case of Korea. Appl. Econ. 2018, 50, 757-773. [CrossRef]

45. Ryu, D. Implied volatility index of KOSPI200: Information contents and properties. Emerg. Mark. Fin. Trade 2012, 48, 24-39. [CrossRef]

46. Ryu, D.; Kang, J.; Suh, S. Implied pricing kernels: An alternative approach for option valuation. J. Fut. Mark. 2015, 35, 127-147. [CrossRef]

47. Ryu, D.; Yang, H. Noise traders, mispricing, and price adjustments in derivatives markets. Eur. J. Fin. 2020, 26, 480-499. [CrossRef]

48. Ryu, D.; Yang, H. Who has volatility information in the index options market? Fin. Res. Lett. 2019, 30, $266-270$. [CrossRef]

49. Ryu, D.; Ryu, D.; Yang, H. Vega-informed trading and options market reform. Appl. Econ. Lett. 2020, $27,19-24$. [CrossRef]

50. Yang, H.; Kutan, A.M.; Ryu, D. Volatility information trading in the index options market: An intraday analysis. Int. Rev. Econ. Fin. 2019, 64, 412-426. [CrossRef]

51. Black, F. Studies of stock market volatility changes. In Proceedings of the Business and Economics Statistics Section; American Statistical Association: Washington, DC, USA, 1976; pp. 177-181. Available online: http://www.economicsejournal.org/economics/journalarticles/2013-3/references/Black1976 (accessed on 2 May 2020).

52. Christie, A.A. The stochastic behavior of common stock variances: Values, leverage, and interest rate effects. J. Fin. Econ. 1982, 10, 407-432. [CrossRef]

53. Pindyck, R.S. Uncertainty in the theory of renewable resource markets. Rev. Econ. Stud. 1984, 51, $289-303$. [CrossRef]

54. French, K.R.; Schwert, G.W.; Stambaugh, R.F. Expected stock returns and volatility. J. Fin. Econ. 1987, 19, 3-29. [CrossRef]

55. Campbell, J.Y.; Hentschel, L. No news is good news: An asymmetric model of changing volatility in stock returns. J. Fin. Econ. 1992, 31, 281-318. [CrossRef]

56. Hibbert, A.M.; Daigler, R.T.; Dupoyet, B. A behavioral explanation for the negative asymmetric return-volatility relation. J. Bank. Fin. 2008, 32, 2254-2266. [CrossRef]

57. Han, Q.; Guo, B.; Ryu, D.; Webb, R.I. Asymmetric and negative return-volatility relationship: The case of the VKOSPI. Invest. Anal. J. 2012, 41, 69-78. [CrossRef]

58. Kroner, K.F.; Ng, V.K. Modeling asymmetric comovements of asset returns. Rev. Fin. Stud. 1998, 11, 817-844. [CrossRef]

59. Koutmos, G. Asymmetric price and volatility adjustments in emerging Asian stock markets. J. Bus. Fin. Account. 1999, 26, 83-101.

60. Lee, B.S.; Ryu, D. Stock returns and implied volatility: A new VAR approach. Economics 2013, 7, 1-20. [CrossRef]

61. Engle, R.F.; Ng, V.K. Measuring and testing the impact of news on volatility. J. Fin. 1993, 48, 1749-1778. [CrossRef]

62. Engle, R.F.; Kroner, K. Multivariate simultaneous generalized ARCH. Econ. Theory 1995, 11, $122-150$. [CrossRef]

63. Engle, R. Dynamic conditional correlation: A simple class of multivariate generalized autoregressive conditional heteroskedasticity models. J. Bus. Econ. Stat. 2002, 20, 339-350.

(C) 2020 by the authors. Licensee MDPI, Basel, Switzerland. This article is an open access article distributed under the terms and conditions of the Creative Commons Attribution (CC BY) license (http://creativecommons.org/licenses/by/4.0/). 